\title{
PERANCANGAN DAN PEMBUATAN SISTEM INFORMASI PERPUSTAKAAN PADA SDN 26 MATARAM
}

\author{
(Designing and Manufacturing of Library Information System at SDN 26 \\ Mataram) \\ Nanda Wafiya ${ }^{[1]}$, Nadiyasari Agitha ${ }^{[1]}$, Muliadi $^{[2]}$ \\ ${ }^{[1]}$ Dept Informatics Engineering, University of Mataram \\ J1. Majapahit 62, Mataram, Lombok NTB, INDONESIA \\ ${ }^{[2]}$ Sekolah Dasar Negeri 26 Mataram \\ Jl. Gunung Kerinci no. 15A, Dasan Agung Baru, Mataram, Lombok NTB, INDONESIA \\ Email: nandawafiya01@gmail.com, nadiya@unram.ac.id,muliadi@gmail.com
}

\begin{abstract}
Abstrak
Manajemen perpustakaan yang terkomputerisasi menggunakan Microsoft Excel saat ini sudah banyak digunakan. Namun Microsoft excel masih memiliki banyak kekurangan dalam penggunaanya seperti, data dapat hilang sewaktuwaktu, human error dan untuk penggunaan bersama masih kurang tepat digunakan karena user yang lain akan kesulitan jika ingin melakukan update data karena data tidak tersimpan pada database terpusat. Kekurangan tersebut dapat diatasi dengan membuat sebuah sistem informasi perpustakaan berbasis website menggunakan bahasa pemrograman PHP dan database MySQL. Metode perancangan sistem yang digunakan yaitu menggunakan metode waterfall. Untuk mensosialisasikan penggunaan Sistem Informasi perpustakaan kepada pengguna akhir, dilakukan dari tahap perencanaan, persiapan, pelaksanaan dan evaluasi. Hasil dari pengabdian ini didapat seluruh responden di SDN 26 Mataram setuju dengan sistem yang dibuat dan dapat menggunakannya.

Keywords: Sistem Informasi, PHP, MySQL, Metode Waterfall, Perpustakaan
\end{abstract}

\section{Pendahuluan}

\subsection{Latar Belakang}

Sekolah Dasar Negeri 26 merupakan sekolah dasar negeri yang berada di kota Mataram. Sebagai salah satu sekolah dasar, tentunya Sekolah Dasar Negeri 26 memiliki tujuan untuk mencerdaskan dan membuat siswa gemar membaca buku. Oleh karena itu Sekolah Dasar Negeri 26 Mataram memiliki perpustakaan sebagai penunjang untuk mencapai tujuan tersebut.

Perpustakaan sekolah adalah perpustakaan yang ada di sekolah sebagai sarana pendidikan untuk menunjang pencapaian tujuan pendidikan prasekolah, pendidikan dasar, dan pendidikan menengah. Selain itu perpustakaan sekolah juga memberi pelayanan kepada murid dan guru dalam proses belajar mengajar. Perpustakaan sekolah merupakan bagian penting dalam proses pendidikan, bagi pengembangan literasi, literasi informasi, pengajaran, pembelajaran dan kebudayaan [1].

Perpustakaan di Sekolah Dasar Negeri 26 Mataram saat ini sudah terkomputerisasi. Dimana data-data buku, anggota, peminjaman dan pengembalian diolah menggunakan Microsoft Excel. Pengolahan data menggunakan Microsoft Excel masih kurang tepat untuk digunakan. Salah satu kekurangannya yaitu dalam penyimpanan data. Data tersimpan dalam bentuk file sehingga data dapat hilang sewaktu-waktu selain itu juga untuk penggunaan bersama Microsoft excel masih kurang tepat digunakan karena data tidak tersimpan pada database sehingga user yang lain akan kesulitan mengupdate data.

Sistem informasi merupakan kombinasi teratur dari orang-orang, perangkat keras, perangkat lunak, jaringan komunikasi, dan sumber daya yang mengumpulkan, mengubah, dan menyebarkan informasi dalam sebuah organisasi. Selain itu sistem informasi adalah kombinasi atau gabungan dari orang-orang, perangkat keras, perangkat lunak, dan sumber daya yang mampu mengumpulkan, mengolah, mengubah dan menyebarkan informasi dalam sebuah organisasi [2]. Sistem informasi memiliki kriteria yaitu fleksibel, efektif dan efesien. 
Sistem informasi ada yang berbasis desktop dan ada yang berbasis website. Seiring perkembangan zaman sistem informasi berbasis desktop semakin banyak ditinggalkan oleh penggunanya karena dirasa kurang fleksibel. Keamanan sistem informasi berbasis desktop masih dianggap lemah sehingga saat ini banyak pengguna yang beralih menggunakan sistem informasi yang berbasis website yang memiliki keamanan lebih ketat karena jika terjadi kebocoran keamanan dapat lebih mudah diperbaiki hanya dengan memperbaiki disatu tempat saja. Selain itu sistem informasi berbasis website juga dapat diakses dimana saja dan kapan saja. Sistem informasi berbasis website juga tidak hanya dapat diakses melalui personal computer saja namun dapat juga diakses melalui smartphone dan tablet.

Berdasarkan hal tersebut, maka perlu dibuat sistem informasi perpustakaan berbasis website. Pembuatan sistem informasi perpustakaan ini yaitu agar dapat menangani masalah pendataan dan pengolahan data pada perpustakaan Sekolah Dasar Negeri 26 Mataram. Dengan adanya sistem informasi perpustakaan ini diharapkan dapat memberikan kemudahaan untuk pengolahan data perpustakaan Sekolah Dasar Negeri 26 Mataram.

\subsection{Rumusan Masalah}

Berdasarkan latar belakang diatas dapat ditarik rumusan masalah yaitu bagaimana cara merancang dan membangun sistem informasi perpustakaan berbasis website pada Sekolah Dasar Negeri 26 Mataram ?

\subsection{Tujuan}

Berdasarkan latar belakang diatas, tujuan perancangan dan pembuatan sistem informasi perpustakaan berbasis website ini yaitu untuk menyelesaikan permasalahan pendataan dan pengolahan data yang terjadi pada perpustakaan Sekolah Dasar Negeri 26 Mataram.

\subsection{Manfaat}

Manfaat pembuatan sistem informasi perpustakaan berbasis website untuk Sekolah Dasar Negeri 26 Mataram :

a. Pengolahan data perpustakaan menjadi lebih mudah .

b. Pengolahan data tidak memakan waktu yang lama.

c. Data sewaktu-waktu tidak mudah hilang.

\section{Tinjauan Pustaka}

\subsection{Sistem Informasi}

Sistem informasi merupakan suatu sistem di dalam organisasi yang mempertemukan kebutuhan pengolahan transaksi harian, mendukung operasi, bersifat manajerial dan kegiatan strategi dari suatu organisasi dan menyediakan pihak luar tertentu dengan laporan-laporan yang diperlukan. Jadi perancangan sistem informasi merupakan pengembangan sistem baru dari sistem lama yang ada, dimana masalah-masalah yang terjadi pada sistem lama di harapkan sudah teratasi pada sistem yang baru [3]. Sistem informasi memiliki beberapa kelebihan, dengan menggunakan sistem informasi, komunikasi menjadi lebih akurat dan cepat, dapat menyimpan informasi dalam jumlah besar dalam ruang yang kecil, dapat diakses oleh banyak orang dengan cepat dan mudah.

\subsection{Perpustakaan}

Perpustakaan sekolah adalah perpustakaan yang ada di sekolah sebagai sarana pendidikan untuk menunjang pencapaian tujuan pendidikan prasekolah, pendidikan dasar, dan pendidikan menengah serta memberi pelayanan kepada murid dan guru dalam proses belajar mengajar [1].

Pada era digital saat ini, perpustakaan digital menjadi pilihan terbaik untuk digunakan. Perpustakaan digital adalah perpustakaan modern yang sudah menggunakan sistem otomasi dalam operasionalnya serta mempunyai koleksi bahan pustaka sebagian besar dalam bentuk format digital yang disimpan dalam arsitektur komputerisasi dan bisa diakses melalui computer [4].

\subsection{Aplikasi Berbasis Web}

Aplikasi web juga merupakan suatu aplikasi perangkat lunak computer yang dikodekan dalam bahasa yang didukung penjelajah web (Seperti HTML, JavaScript, AJAX, Java, dll) dan bergantung pada penjelajah tersebut untuk menampilkan aplikasi. Aplikasi web menjadi popular karena kemudahan tersedianya aplikasi klien untuk mengaksesnya, penjelajah web, yang kadang disebut sebagai thin client [5].

\subsection{Observasi}


Observasi merupakan salah satu kegiatan ilmiah empiris yang mendasarkan fakta-fakta lapangan maupun teks, melalui pengalaman panca indra tanpa menggunakan manipulasi apapun. Tujuan dari observasi adalah deskripsi, pada penelitian kualitatif melahirkan teori dan hipotesis, atau pada penelitian kuantitatif digunakan untuk menguji teori dan hipotesis. Untuk dapat mendekati fenomena sosial, seorang observer atau pengamat perlu memiliki kedekatan akses dengan setting dan subjek penelitian [7].

\subsection{Wawancara}

Wawancara adalah situasi berhadap-hadapan antara pewawancara dan responden yang dimaksudkan untuk menggali informasi yang diharapkan, dan bertujuan mendapatkan data tentang responden dengan minimum bias dan maksimum efisiensi. Terdapat dua macam wawancara yaitu wawancara formal dan informal. Wawancara formal atau disebut juga wawancara terstruktur adalah sebuah prosedur sistematis untuk menggali informasi mengenai responden dengan kondisi dimana satu set pertanyaan ditanyakan dengan urutan yang telah disiapkan oleh pewawancara dan jawabannya direkam dalam bentuk yang terstandardisasi [8].

\subsection{Sumber Data}

Sumber data dalam penelitian adalah subjek dari mana data diperoleh. Apabila peneliti menggunakan kuesioner atau wawancara dalam pengumpulan datanya, maka sumber data disebut responden, yaitu orang yang merespon atau menjawab pertanyaanpertanyaan peneliti, baik pertanyaan tertulis ataupun lisan. Klasifikasi sumber data, dilihat dari subjek di mana data menempel, yang disingkat dengan 3 P yaitu person, place dan paper. Sumber data dibagi menjadi dua yaitu sumber data primer dan sumber data sekunder[10].

\section{Metode Pengabdian MASYARAKAT}

Ada beberapa tahapan dalam proses pengabdian masyarakat pada perancangan dan pembuatan sistem informasi perpustakaan di Sekolah Dasar Negeri 26 Mataram. Tahapah tersebut di gambarkan pada diagram alir berikut ini :

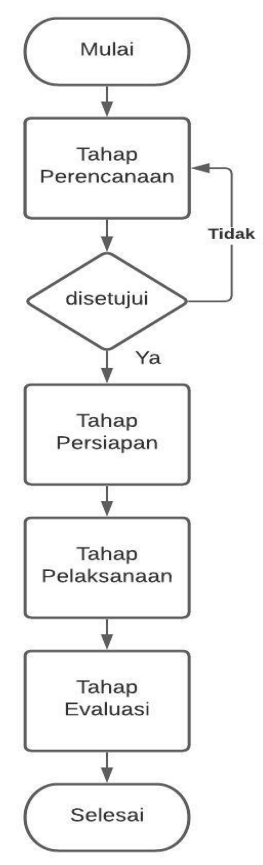

Gambar 1. Diagram Alir Pengabdian Masyarakat

\subsection{Tahap perencanaan}

Tahap perencanaan adalah tahap awal yang dilakukan dengan melakukan observasi terhadap management perpustakaan dan wawancara dengan operator serta beberapa pihak yang berada di Sekolah Dasar Negeri 26 Mataram. Observasi dan wawancara ini dilakukan untuk mengidentifikasi masalah yang terjadi pada management perpustakaan. Selain itu observasi dan wawancara ini juga berfungsi untuk menganalisis kebutuhan dengan menganalisis sistem sebelumnya dengan sistem yang akan dibuat. 


\subsection{Tahap persiapan}

Tahap persiapan yaitu tahapan untuk mempersiapkan kebutuhan yang akan digunakan untuk merancang dan membangun sistem informasi perpustakaan di Sekolah Dasar Negeri 26 Mataram. Pada tahap ini dilakukan persiapan seperti penentuan metode yang akan digunakan untuk merancang sistem dan pembuatan desain sistem. Metode pengembangan yang digunakan untuk pengembangan perangkat lunak adalah model atau paradigma klasik yang sering disebut waterfall [9]. Dalam pengembangannya metode waterfall memiliki beberapa tahapan yang runtut: requirement (analisis kebutuhan), design sistem, Coding \& Testing, Penerapan Program, pemeliharaan.

\subsection{Tahap pelaksanaan}

Tahap pelaksanaan yaitu tahapan untuk melakukan pembuatan sistem informasi perpustakaan di Sekolah Dasar Negeri 26 Mataram. Pembuatan sistem informasi ini dilakukan dengan mengikuti metode perancangan sistem yang telah ditentukan. Setelah melakukan perancangan dan pembuatan sistem maka selanjutnya melakukan sosialisasi penggunaan sistem kepada operator, guru dan kepala sekolah yang ada di Sekolah Dasar Negeri 26 Mataram.

\subsection{Tahap Evaluasi}

Tahap evaluasi merupakan tahapan akhir dalam pembuatan sistem. Pada pembuatan sistem informasi perpustakaan ini, evaluasi dilakukan dengan cara memberikan kuisioner kepada operator, guru dan kepala sekolah. Evaluasi ini bertujuan untuk mengetahui bagaimana kepuasan pelanggan terhadap kinerja sistem yang telah dibuat.

\section{Hasil dan Pembahasan}

Pada tahapan awal pembuatan sistem informasi perpustakaan di Sekolah Dasar Negeri 26 Mataram dilakukan wawancara dengan pihak dari Sekolah Dasar Negeri 26 Mataram. Hasil dari wawancara yaitu bahwa perpustakaan di Sekolah Dasar Negeri 26 Mataram sudah terkomputerisasi menggunakan Microsoft Excel. Namun penggunaan Microsoft Excel tersebut masih memiliki kekurangan. Salah satu kekurangannya yaitu dalam penyimpanan data. Data tersimpan dalam bentuk file sehingga data dapat hilang sewaktu-waktu selain itu juga untuk penggunaan bersama Microsoft excel masih kurang tepat digunakan karena data tidak tersimpan pada database sehingga user yang lain akan kesulitan dalam mengupdate data.

Pada saat pembuatan sistem, penulis tetap berkomunikasi dengan operator yang ada di Sekolah Dasar Negeri 26 Mataram. Komunikasi ini dilakukan untuk berkonsultasi mengenai sistem yang sedang dibuat agar proses pembuatan sistem berjalan dengan lancar. Selain itu juga komunikasi ini bertujuan agar sistem dibuat sesuai dengan keinginan pelanggan.

Setelah pembuatan sistem maka dilakukan sosialisasi atau pelatihan mengenai cara pengoperasian sistem informasi perpustakaan kepada operator, guru dan kepala sekolah Sekolah Dasar Negeri 26 Mataram. Selain itu juga diadakan pengujian sistem informasi perpustakaan. Pengujian sistem informasi ini menggunakan metode user acceptance testing. Metode user acceptance testing menggunakan black box testing dan kuesioner dalam pengujiannya. Berikut hasil dari pengujian yang telah dilakukan:

\subsection{Black Box Testing}

Metode pengujian black box merupakan metode pengujian yang menguji fungsi-fungsi di dalam sistem untuk menentukan apakah fungsi-fungsi tersebut sudah berjalan sesuai harapan atau tidak [6]. Pengujian black box dilakukan dengan cara melakukan testing seluruh fitur yang ada dengan memasukkan data yang dibutuhkan pada sistem informasi perpustakaan. Seluruh fitur yang diuji berhasil dijalankan dengan baik.

\subsection{Kuesioner}

http://begawe.unram.ac.id/index.php/JBTI/ 
Untuk mengetahui tanggapan responden terhadap sistem informasi perpustakaan yang telah diimplementasikan, maka dilakukan pengujian dengan memberikan 6 pertanyaan kepada 9 responden yang terdiri dari guru, operator, dan petugas dimana hasil respon dari pertanyaan tersebut dapat dilihat pada tabel dibawah ini :

\begin{tabular}{|c|l|c|c|}
\hline No & \multicolumn{1}{|c|}{ Pertanyaan } & \multicolumn{2}{|c|}{ Jawaban } \\
\cline { 2 - 4 } & \multicolumn{1}{|c|}{ Ya } & Tidak \\
\hline 2 & $\begin{array}{l}\text { Apakah sistem yang dibuat sudah } \\
\text { sesuai dengan kebutuhan pada SDN 26 } \\
\text { Mataram? }\end{array}$ & 9 & \\
\hline & $\begin{array}{l}\text { Apakah sistem yang dibuat dapat } \\
\text { mempermudah pegawai dalam } \\
\text { mengelola data dan peminjaman buku } \\
\text { di perpustakaan? }\end{array}$ & 9 & \\
\hline 3 & $\begin{array}{l}\text { Apakah sistem yang dibuat mudah } \\
\text { digunakan? }\end{array}$ & 9 & \\
\hline 4 & $\begin{array}{l}\text { Apakah sistem menghasilkan } \\
\text { informasi yang detail? }\end{array}$ & 9 & \\
\hline 5 & $\begin{array}{l}\text { Dalam hal tata letak (design), apakah } \\
\text { sistem mudah untuk dibaca dan } \\
\text { dipahami? }\end{array}$ & 9 & \\
\hline 6 & $\begin{array}{l}\text { Apakah sistem sudah bekerja sesuai } \\
\text { dengan kegunaan dan fungsinya? }\end{array}$ & 9 & \\
\hline
\end{tabular}

Tabel 1. Hasil Kuisioner

Dapat dilihat pada tabel semua responden menjawab "Ya" pada ke 6 pertanyaan yang diajukan penulis. Dari sini dapat disimpulkan bahwa sistem informasi perpustakaan yang dibuat sudah sesuai dengan kebutuhan dan sudah bekerja sesuai kegunaan dan fungsinya. Selain itu juga sistem yag dibuat dapat digunakan dengan mudah oleh pengguna.

Berikut implementasi sistem informasi perpustakaan sekolah Dasar Negeri 26 Mataram

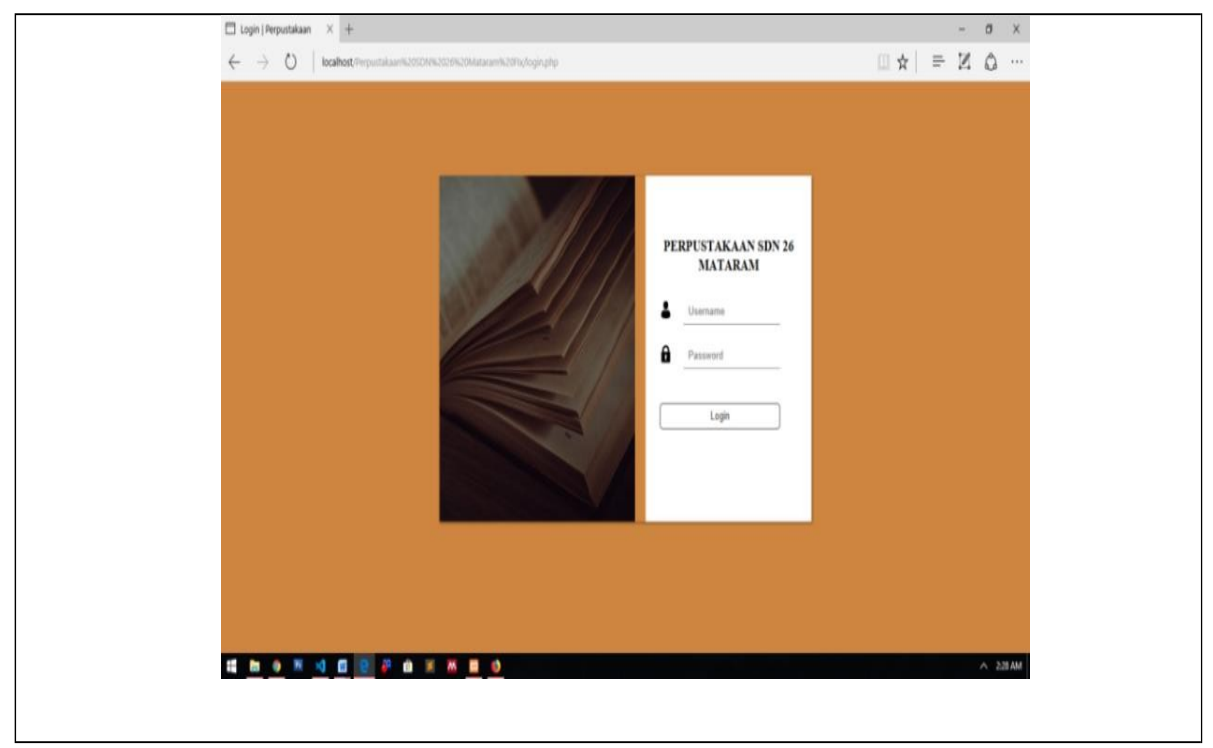




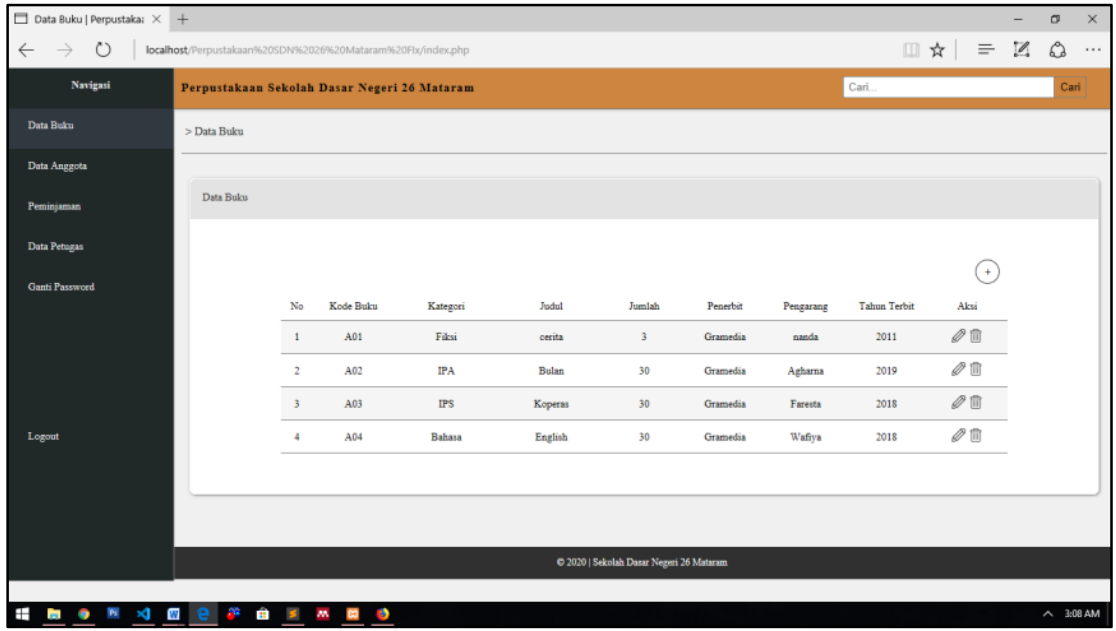

Gambar 3. Halaman Data Buku

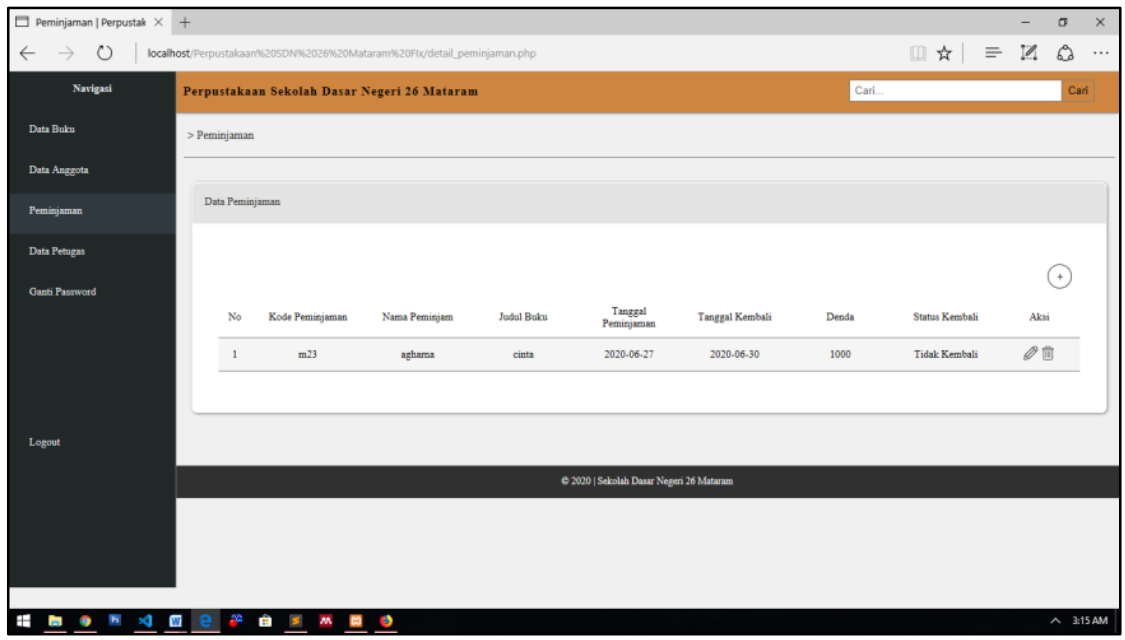

Gambar 4. Halaman Peminjaman

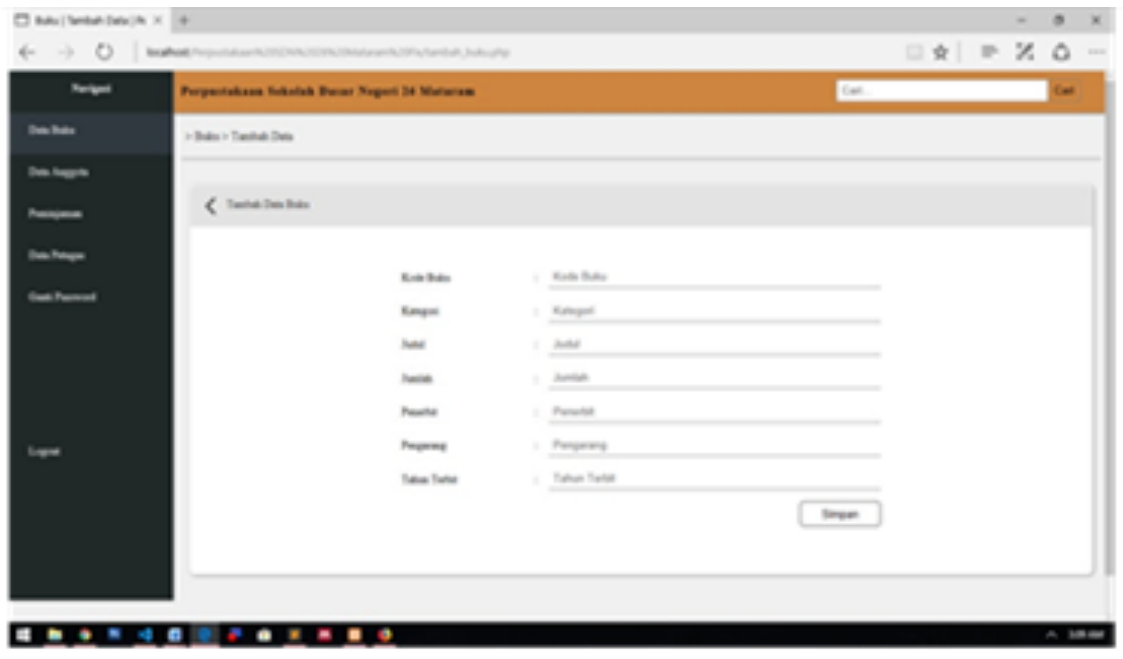

Gambar 5. Halaman Tambah Data Buku 


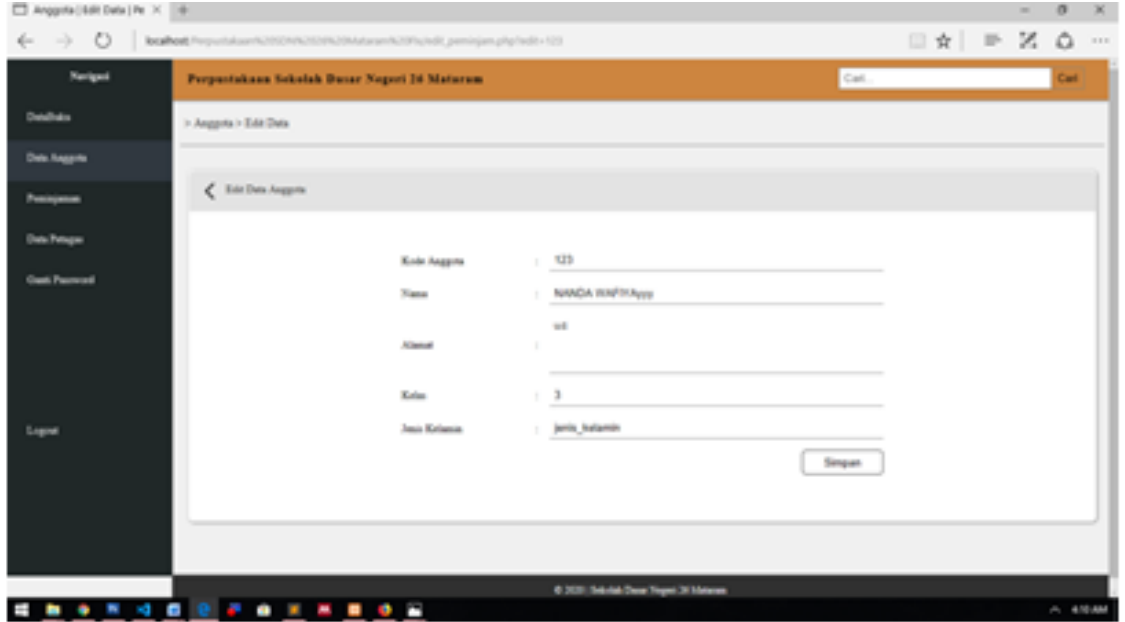

Gambar 6. Halaman Edit Data Buku

\section{KESIMPULAN DAN SARAN}

\section{$5.1 \quad$ Kesimpulan}

Rancangan Sistem Informasi perpustakaan pada Sekolah Dasar Negeri 26 Mataram dibuat berdasarkan hasil analisis terhadap kebutuhan sistem perpustakaan SD Negeri 26 Mataram. Sistem informasi perpustakaan berfungsi untuk mendata buku, anggota dan peminjaman. Analisis kebutuhan didapatkan dengan cara melakukan observasi dan wawancara terhadap pihak Sekolah Dasar Negeri 26 Mataram.

Dalam mengelola dan menyajikan sistem informasi perpustakaan pada Sekolah Dasar Negeri 26 Mataram maka dibuat sistem informasi berbasis web dengan bahasa pemrograman PHP dan MySQL. Hal ini dapat mempermudah petugas dalam mendata buku,anggota dan peminjaman. Selain itu juga pembuatan sistem ini dapat menjaga data agar tetap aman dan tidak hilang sewaktu-waktu

Kepuasan client terhadap sistem yang telah dibuat dapat dilihat dari respon client terhadap pertanyaanpertanyaan yang ada di kuisioner yang diberikan. Dari hasil kuisioner 9 responden dapat dilihat, setiap responden menjawab "Ya" disetiap pertanyaannya. Jadi dapat disimpulkan client sudah puas terhadap sistem yang dibuat.

\subsection{Saran}

Adapun saran yang dapat diberikan penulis yaitu diharapkan untuk mengembangkan sistem informasi perpustakaan agar tidak hanya dapat digunakan oleh admin saja namun dapat juga digunakan oleh anggota perpustakaan. Selain itu diharapkan agar system informasi perpustakaan ini digunakan dengan sebaik mungkin.

\section{UCAPAN TERIMA KASIH}

Ucapan terimakasih ditujukan kepada Allah SWT. yang telah memberikan rahmat dan karunianya kepada penulis. Dalam kesempatan ini, penulis juga ingin mengucapkan banyak terimakasih kepada seluruh dosen Program Studi Teknik Informatika Universitas Mataram yang telah memberikan ilmu. Terimakasih juga penulis sampaikan kepada seluruh pihak Sekolah Dasar Negeri 26 Mataram yang telah membantu dan bekerjasama dalam pembuatan sistem informasi perpustakaan ini.

\section{DAFTAR PUSTAKa}

[1] M. Yunarko, “Evaluasi Pemanfaatan Perpustakaan Sebagai Pusat Sumber Belajar Di Sekolah Menengah Pertama (SMP) Negeri 5 Blambangan". 2015.

[2] Yakub, "Pengantar Sistem Informasi. Yogyakarta": Graha Ilmu. 2012.

[3] A. Firman, H. F. Wowor, and X. Najoan, "Sistem Informasi Perpustakaan Online Berbasis Web," 2016.

[4] D. Dan and S. Perpustakaan, "Desain Dan Standar Perpustakaan Digital," J. Pustak. Indones., vol. 10, no. 2, pp. 17-23, 2010. 
[5] M. Zia'ulhaq, "Penerapan Sistem Informasi Berbasis Web untuk Mendukung Pengelolaan Administrasi di Promusic Recording Studio Jepara". 2014.

[6] Sumiati, Sri Endang Anjarwani, dan Moh. Ali Albar, "Rancang Bangun Sistem Informasi Pengelolaan Surat dan Kearsipan pada Sekretariat Daerah Provinsi NTB Berbasis Web," J-COSINE, vol. 2, no. 1, hal. 7 - 16, Juni 2018.

[7] Hasanah.H, "Teknik-Teknik Observasi". Jurnal at-Taqaddum, Volume 8, Nomor 1. Jul.2018.

[8] Hakim.L, "Ulasan Metodologi Kualitatif : Wawancara Terhadap Elit". Pusat Pengkajian , Pengolahan Data dan Informasi ( P3DI ) Sekertariat Jenderal DPR RI. Aspirasi Vol. 4. Nov 2.

[9] Utama Y, "Sistem Informasi Berbasis Web Jurusan Sistem Informasi Fakultas Ilmu Komputer Universitas Sriwijaya". Fakultas Ilmu Komputer Jurusan Sistem Informasi.2011.

[10] Dalis S, "Rancang Bangun Sistem Informasi Lembaga Penelitian Dan Pengabdian Masyarakat Berbasis Web". Paradigma Vol.19, No.1 . 2017 